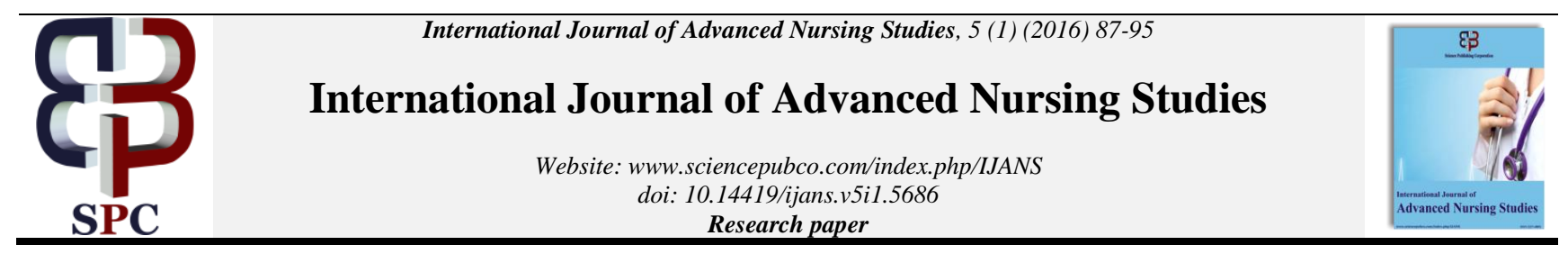

\title{
The effectiveness of the nursing intervention program on feeling of burden and coping among caregivers of children with epilepsy
}

\author{
Maaly I. El Malky ${ }^{1}$, Magda M. Mohsen ${ }^{2}$, Hemat M. Amer ${ }^{2}$ \\ ${ }^{1}$ Mental Health Nursing Department, Faculty of Nursing, Menoufia University, Shebin El-Kom, Egypt \\ ${ }^{2}$ Community Health Nursing Department, Faculty of Nursing, Menoufia University, Shebin El-Kom, Egypt \\ *Corresponding author E-mail: maalyelmalky@yahoo.com
}

\begin{abstract}
Epilepsy is one of the most common pediatric neurological disorders, which have negative psychological, emotional, and physical consequences of providing care. Nursing intervention is a key element of managing these patients and their families in order to reduce feelings of burden and enhancing coping among caregivers. Aim: To evaluate the effectiveness of nursing intervention on a feeling of burden and coping among caregivers of children with epilepsy. Design: A quasi-experimental design (one group pretest-posttest design) was used to achieve the aim of the study. Setting: The study was conducted at the outpatient clinic at the health insurance institute in Shebin El-Kom district, Menoufia Governorate. Subject: A convenience sample of 80 caregivers was used. Tool: I- A constructed interviewing questionnaire was developed by researchers to assess socio demographic data, medical history and family caregiver's knowledge, practices and opinions regarding child with epilepsy. II- Modified version of the Zarit burden interviewing questionnaire to assess feeling of burden. III- Coping Health Inventory for Parents to assess coping patterns of care giver's. The Results: the main finding of this study illustrated that, there were statistical significance differences regarding caregivers' knowledge and practices. Reduction of the feeling of burden and improvement of coping patterns after nursing intervention than before. There was a negative correlation between caregiver's knowledge, practice and feeling of burden and there was a positive correlation between (KPO) and coping among caregivers. The majority of the studied caregivers were mothers $(76 \%)$ with mean age score $37.21 \pm 5.22$, more than half were secondary education, and the majority (75\%) was not working. Conclusion: Nursing intervention was effective in improving caregiver's knowledge, practices and opinions, feeling of burden and raising coping abilities for caregivers of children with epilepsy. Recommendation: additional nursing strategies are needed around the time of the diagnosis with longitudinal assessment and follow up for both caregivers and their children.
\end{abstract}

Keywords: Epilepsy Children; Nursing Intervention Program; Burden and Coping among Caregivers.

\section{Introduction}

Epilepsy is a chronic illness usually diagnosed after the occurrence of three or more seizures (Windland-Brown \& Rhoads, 2007). Epilepsy occurs most often in children between the ages of three and five, or adults ages 65 and older .Epilepsy defined as "a disorder of the brain characterized by an enduring predisposition to generate epileptic seizures and by the neurobiological, cognitive, psychological, and social consequences of this condition. The definition of epilepsy requires the occurrence of at least one epileptic seizure (International League Against Epilepsy and the International Bureau for Epilepsy,2014).A Epilepsy is a chronic condition that can be traumatic for the child with epilepsy and family. Child illness is a critical event that places additional stress and burden on families, beyond those of normal development and this may affect overall family adaptation (Cushner-Weinstein et al. 2008).

Families vary in their ability to cope with childhood epilepsy. The condition has serious physical, psychological, social and economic consequences for the concerned persons and their families. Burden of care is a multi-factorial construct which includes emotional, psychological, physical and economic impact as well as related distressing feelings such as shame, embarrassment, anger, feeling of guilt and self-blame (Awad \&Voruganti, 2008). Without the ability to adapt to having a child with epilepsy, families may not effectively manage the child's disease. Effective management of epilepsy is extremely significant for decreased seizure activity and positive coping and adaptation (Glueckauf et al. 2009). It is important for nurses to have an understanding of the possible negative effects of epilepsy, such as decreased familial coping and adaptation abilities, and increased family stress levels (Scottish Pediatric Epilepsy Network SPEN, 2013).

The role of the community health nurse in epilepsy is to care for the child and his or her family. Advanced practice nurses are often responsible for diagnosing epilepsy and managing the care of children with epilepsy and their families. Advanced practice nurses must have knowledge of interventions for families coping with epilepsy in order to provide strategies for stress management, positive adaptation, and effective coping mechanisms (Schachter, 2009). Nurses' knowledge will allow for better treatment and care of children with epilepsy and their families. Because family may be an important constant in the child's life, it is extremely important for the advanced-practice nurse to provide family centered 
care to children and families coping with epilepsy. Nurses have a responsibility to educate individuals with epilepsy and their families and are involved in the assessment, management and treatment interventions (Epilepsy Foundation, 2009).

\section{Significance of the study}

Epilepsy is a long term neurological condition has a great impact on the lives of patients and their caregivers. Epilepsy currently affects approximately 2.5 million Americans, of which 300,000 are children (Center for Disease Control and Prevention, 2009). Most cases of epilepsy were diagnosed in children under the age of 14 (Epilepsy Foundation, 2009). In Egypt, the prevalence rate of epilepsy was 643.639 as an exploratory data reported by (Center for disease control and prevention (CDC), 2007).

Estimated an age-specific global incidence of 3.5 million people developing epilepsy on an annual basis, $40 \%$ are children under 15 years old. It is well known that having a child diagnosed with a chronic illness, such as epilepsy, is a significant stressor for both children and parents. Its impact can be characterized in terms of social repercussions, such as isolation, prejudice, and unemployment, or in terms of emotional influences, as seen in personal relationship difficulties, negative self-image, and low self-esteem (Wirrell et al. 2008). Child illness is a critical event that places additional stress and burden on families, beyond those of normal development (Cushner-Weinstein et al. 2008). So nursing the intervention program aim is to evaluate the effectiveness of nursing intervention on a feeling of burden and coping among caregivers of children with epilepsy.

\subsection{Operational definitions}

Feeling of burden operationally defined by the obtained score of feeling of burden interviewing questionnaire measured by (Zarit et al. 1986) and modified by the researcher.

Coping operationally defined by the obtained score of coping measured by (McCubbin et al. 1983).

\section{Subjects and methods}

\subsection{The aim of the study}

The aim of the study is to evaluate the effectiveness of nursing intervention on a feeling of burden and coping among caregivers of children with epilepsy.

\subsection{Research hypothesis}

Caregivers, who will participate in the study, will have lower feeling of burden, high level of coping and higher knowledge scores regarding dealing with their epileptic children than before the nursing intervention program.

\subsection{Research design}

A quasi-experimental design (one group pretest-post test design) was used to achieve the aim of the study.

\subsection{Research setting}

The study was conducted in outpatient clinics (neuro-psychiatric clinic) at comprehensive medical collection follow the health insurance institution in the Shebin El- Kom district, at Menoufia Governorate. This institution consisted of three floors, the second floor service children from 0-18 year plus school students.

\subsection{Subjects}

A convenience sample of 80 caregivers of children with epilepsy was selected from chosen setting.

\subsubsection{Inclusion criteria include}

- Both sexes of caregivers for children at age between 3-12 years who were medically diagnosed with epilepsy

\subsubsection{Exclusion criteria include}

- Caregivers with substance abuse.

- Caregivers with chronic physical illness or mental diseases.

\subsection{Instruments of the study}

Three tools were used in the study:

Tool (I): A constructed interviewing questionnaire was developed and utilized by the researcher; it was consisted of three parts: Part one to assess Socio demographic data for caregiver as age, sex, level of education, Job status, and income. Part two to assess family caregiver's knowledge and practices regarding epilepsy. This part consisted of twenty one (21) questions were scored according to 3-point likert scale ranged from 0 to 2 .Total score 42 scored as the following:

- Knowledge about epilepsy: 12 questions, its total scores 24 degree, $(<12$ degree considered unsatisfactory knowledge, while; 12-24 degree is satisfactory).

- -Caregivers' practices about epilepsy: it consists of eight questions, its total scores 16 degree $<8$ degree is poor practice, while 8-16 good practices).

Tool II- Modified Arabic version of Zarit burden interviewing questionnaire (ZBI) .This tool originally developed by (12) translated into Arabic, modified and validated by the researcher. This tool used to measure to what extent the family caregiver have physical, social, and psychological burden as a result of caring their children with epilepsy. By adding 8 questions regarding physical and psychological burden, the burden interview sheet is composed of 29 items. The items of sheet were scored according to 3-point likert scale .The ZBI questionnaire consisted of three main sections: Physical stress, Social stress and Psychological stress due to care given to child with epilepsy as reported by family caregivers: Physical stress was assessed through four questions for the presence or absence of a list of indicating symptoms as headache and sleep disorder were asked. Social stress was assessed through ten questions regarding their families' problems, work problems, and relation with others. Psychological stress was assessed through fifteen questions related to frustration, depression, helplessness.

Total score 58Grade (Mild: 0-19Moderate: 20-38 Severe: 39-58).

Tool III- Coping Health Inventory for Parents (CHIP) developed and validated by (13) were used to measure parental coping strategies. This validated instrument was designed to assess parents' appraisal of behaviors currently in use to manage family life when they have a seriously ill or chronically ill child. It consists of a checklist of 44 specific behaviors. Parents were asked to indicate the presence of a behavior and how the behavior is useful in their particular family situation. The CHIP has three subscales that represent different positive coping patterns. The following is a description of each of the three coping patterns:

Coping Pattern I- identified as Maintaining Family Integration, Cooperation, and an Optimistic Definition of the Situation--is made up of 16 items reflecting behaviors that focus on the family and the parent view on life and the child illness. Items assess parental perceptions of the importance of keeping the family together, encouraging cooperation, involvement in their children lives, and fostering independence in family members.

Coping Pattern II--identified as Maintaining Social Support, Self Esteem, and Psychological Stability--is composed of 19 items reflecting parental efforts to have a personal sense of well-being by obtaining social support from others, maintaining feelings of self-esteem, and dealing with psychological tensions and strains. 
Coping Pattern III--identified as Understanding the Medical Situation through Communication with Other Parents and Consultation with Medical Staff is composed of 9 coping behaviors focusing on the interface between parents and healthcare personnel, as well as other parents in a similar situations. The behaviors reflect parental efforts to understand and master health information needed to cope with the illness.

The tool was translated into Arabic and modified by the researcher, rephrasing the sentences to be suitable for Egyptian language and culture. The scoring also has been modified to be 3-pointlikert scale as the following: $(0=$ Never used, $1=$ Sometimes used and $2=$ always used) instead of 4 point Likert scale as represented $(0=$ not helpful, 1 = minimally helpful, 2 =moderately helpful and $3=$ extremely helpful).The tool was revised by a panel of expert in the field.

The higher the coping score, the increased use of coping. (Total score $=88$. Grade: Mild: 0-29/ Moderate: $>29-<58 /$ high: 58-88).

\subsubsection{Reliability of the tools}

All the tools used in the present study were tested for its reliability by using test retest reliability and the result revealed that all tools were strongly reliable at .83 for tool one, at .97 for tool two and at .93 for tool three.

\subsubsection{Validity of the tools}

The tools of data collection were tested for face and content validity by a panel of experts in community, pediatric and psychiatric health nursing specialty to ascertain relevance and completeness and the required modification was carried out accordingly.

\subsection{Procedure}

Approval: an official permission was obtained from the directors of the above mentioned institution to get permission for data collection. Ethical consideration: Protection of human rights was maintained to all subjects that the participation in research is voluntary. Anonymity and confidentiality of the responses were respected. All subjects have a freedom to refuse participating in the research and withdrawing at any time. A Pilot study: was carried out on eight caregivers for testing a clarity, applicability and nearly time needed to fill each tool. Based on the finding of the pilot study, the necessary modifications were done accordingly, i.e., Likert scale had changed to three points instead of five points in ZBI and in CHIP had changed instead of four points to three points Likert scale. This sample was excluded from the study. Data collection: The data were collected from the outpatient clinic at the health insurance institute in Shebin El-Kom district, at the Menoufia Governorate from neuro-psychiatric outpatient clinic. The system of work is to provide outpatient clinic services twice day in the week on Saturday and on Wednesday. The data were collected through eight months, the time of the study starts from April to November. All caregivers who meeting the inclusion criteria were included in the research, after they accept to participate in the study. The subjects were divided into 8 groups; each group consisted of 10 caregivers. Each group attends 8 sessions, two sessions per week for one month onelhour for each session. Implementation of the study passed into three phases (pre assessment phase, implementation phase and post assessment phase).

\subsubsection{Pre assessment phase}

A comfortable, private place was chosen for the interview. Orientation was made my name, purpose, significance, content and procedure of the counseling. Subjects were interviewed individually at an outpatient clinic where pre- assessment was done using tools for data collection.

\subsubsection{Implementation phase}

The study hypothesized that application of the nursing intervention program will improve knowledge, reducing a feeling of burden and increasing coping skills of caregivers having children with epilepsy. This intervention program was developed and have its general objectives and given through sessions; each session has a set of specific objectives. This was achieved through several teaching methods as: brain storming, lecture, discussion and role play intervention booklet. Use illustrative media, e.g., computer, video and pictures. At the end of each session summary and conclusion, let a time for asking questions, feedback and give a homework assignment for the next session.

The intended learning outcome objectives for the educational nursing intervention sessions were:

- Define epilepsy

- Identify causes, precipitating factors and general signs and symptoms.

- List types and features of epilepsy.

- State the different treatment regimen according to the child's condition

- Design plan of care according to the child's condition

- Set measures to protect the child from dangers during and after fits

- Accommodate with any progressive changes in the child disease

- Practice plan of care for the child (drugs, eating, school, and activity of daily living)

- Make the environment free from factors increase the frequency of fits.

- Provide first aid in case of crisis.

- Accept the child disease as it like any chronic disease

- Normalize the internal feeling of burden in the form of respite care \& asking help when needed.

- Use effective coping strategies to reduce a feeling of burden and increase coping level.

The sessions of intervention were:

Session 1: This session was concerned with open discussion for identification, integration of group, clarification of the aim, time table allowed for the intervention and distribution of intervention booklet.

Session 2: This session was concerned with knowledge about epilepsy, myths and misconception, features of epileptic fits and causes of epilepsy

Session 3: This session was concerned with how to deal with general and partial seizures and complication related to epileptic fits.

Session 4: This session was concerned with a guidance plan for caregivers related to child educational achievement, nutrition and exercise.

Session 5: This session was concerned with pharmacological treatment (importance of compliance with medication, side effects).

Session 6: This session was concerned the unexpected behaviors related epilepsy, stigma and how to deal with it.

Session 7\& 8: This session was concerned with stress management strategies to improve coping and adaptation with the disease.

\subsubsection{Post assessment phase}

The researcher-encouraged participants to ask questions about the information we're given in the previous sessions. The intervention evaluation was done using pre mentioned tools of data collection.

\subsection{Statistical analysis}

The results were statistically analyzed by statistical product of services solution SPSS version 20 Two types of statistics were done:

a) Descriptive: e.g., percentage (\%), mean and standard deviation SD 
b) Analytical: - A Chi-Squared ( $\chi 2)$ : It is used to compare between two groups or more regarding one qualitative variable.

- McNemars test: is a statistical test used for paired nominal data.

- C Paired t-test: It is a single test used to collectively indicate the presence of any significant difference between different time sequences for a normally distributed quantitative variable.

- Wilcoxon signed rank test: It is the non-parametric version of Paired t test. It is a single test used to collectively indicate the presence of any significant difference between different time sequences for a not normally distributed quantitative variable.

- P value:

- $\quad$ Significant difference if $\mathrm{P}<0.05$

- Non-significant difference if $\mathrm{P}>0.05$.

- Highly significant difference if $\mathrm{P}<0.001$.

\subsection{Limitation of the study}

- $\quad$ Lack of the studies related to specific age group (caregivers of preschool and school age) and statistics about the magnitude of the problem in Egypt, which make difficulty in calculating sample size, also, make the sample to be convenient and the sample size was not large.

\section{Results}

Figure (1): Show the effectiveness of nursing intervention on the caregivers' knowledge score about epilepsy among studied group post intervention. This figure illustrates that, the total satisfactory knowledge score pre nursing intervention was $28.80 \%$, improved to $88.75 \%$ post nursing intervention.

Figure (2): Show the effectiveness of nursing intervention on caregivers' total score of the practices about epilepsy among studied caregivers post intervention. This figure reveals that, more than half $53.80 \%$ of studied caregivers have good practices about epilepsy pre nursing intervention that were improved to $93.80 \%$ post nursing intervention.

Table (1): show the effectiveness of nursing intervention on the mean score of different type of feeling, of burden among caregiver of the studied sample post intervention. This table reveals that there is a reduction in the mean score of different type of feeling of burden and total mean sore of feeling of burden among the studied caregiver post intervention with highly statistically significant difference than before intervention mean score at point $\mathrm{p}<0.001$.

Figure (3): Show the effectiveness of nursing intervention on a caregiver level of burden among studied caregivers post intervention. This figure illustrates that the majority of studied caregivers has severe burden $72.5 \%$ pre nursing intervention, which decreased to $7.5 \%$ post nursing intervention.

Figure (4): Show the effectiveness of nursing intervention on the caregivers' level of coping among studied caregivers post inter- vention. This figure shows that the minorities of studied caregivers $7.50 \%$ have high coping pre nursing intervention, which increased to $75 \%$ high coping post nursing intervention.

Table (2): Show the effectiveness of nursing intervention on the mean score of different type of coping among studied care giver post intervention. This table reveals that there are increases in the mean score of different type of coping and in the total mean score of coping post intervention among the studied caregiver with highly statistically significant difference than pre intervention mean score at point $\mathrm{p}<0.001$

Table (3): Shows relationship between socio demographic characteristics and level of burden among studied caregivers pre post nursing intervention. This table reveals that there is a statistical significant relation between studied caregiver's level of burden pre nursing intervention and socio demographic characteristics regarding the level of education and income at $p<0.05$. While, there were no statistical significant relation between studied caregivers socio demographic characteristics and level of burden post nursing intervention.

Table (4): Show the relationship between studied caregivers Socio demographic characteristics and level of coping pre post nursing intervention. This table illustrates that, there is a highly statistically significant relation between studied the caregiver's level of education and level of coping pre nursing intervention at point $\mathrm{p}<0.001$. Also, there is a statistical significant relation between level of coping and both job status and income at point $\mathrm{p}<0.05$. Regarding post intervention there is statistical highly statistical significance relation between studied caregivers marital status and level of coping at point 0.001 , Also, there is highly statistically significant relation between level of coping and place of residence at a $p$ value $<0.001$

Table (5): show correlation between knowledge and practices about epilepsy and level of burden pre- post test nursing intervention among studied caregivers. This table reveals that there is a statistical significant negative correlation between studied caregivers knowledge $\mathrm{p}<0.001$, practice $\mathrm{p}<0.05$ and opinions $\mathrm{p}<0.05$ and level of burden pre nursing intervention. In addition, there is a statistically significant negative correlation between knowledge ( $p<0.001$ ), opinions $(p<0.05)$ and level of burden post nursing intervention, i.e. when caregiver's knowledge, opinions and practices KOP improved, burden level decrease accordingly. While, there is no statistical significance correlations between studied caregivers practices and level of burden post nursing intervention. Table (6): Shows correlation between knowledge and practices about epilepsy and level of coping pre- post test nursing intervention among studied caregivers. This table shows that there is a high statistical positive correlation between studied caregivers knowledge and level of coping at point $\mathrm{p}<0.001$ at both pre and post nursing intervention. In addition, there were statistical positive correlations between practice $(\mathrm{p}<0.05)$ and opinions $(\mathrm{p}<0.001)$ and level of coping pre nursing intervention, i.e. When knowledge, opinions and practices of caregivers improved, coping abilities also increased.

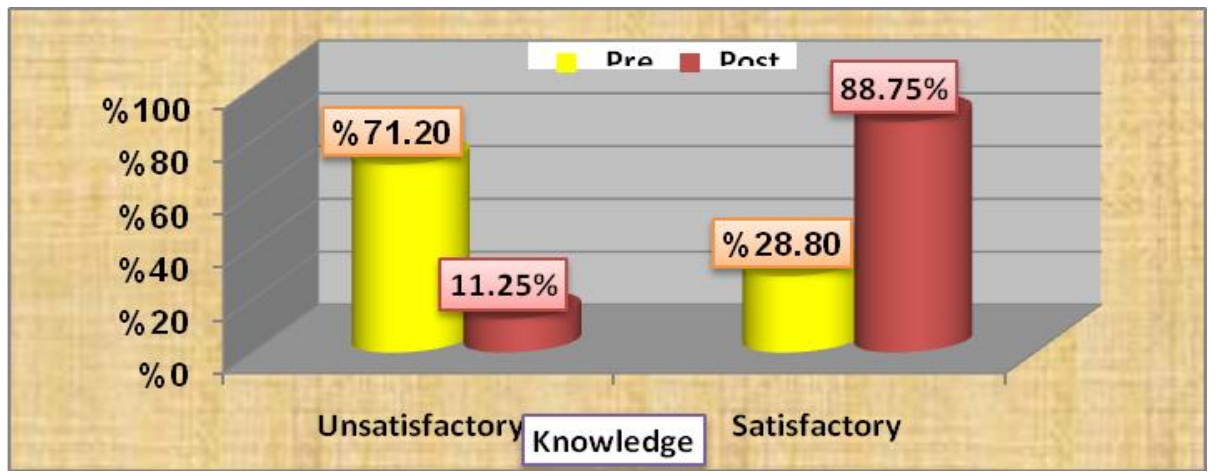

Fig. 1: Effectiveness of Nursing Intervention on Caregivers' Knowledge Score about Epilepsy among Studied Group Post Intervention. 


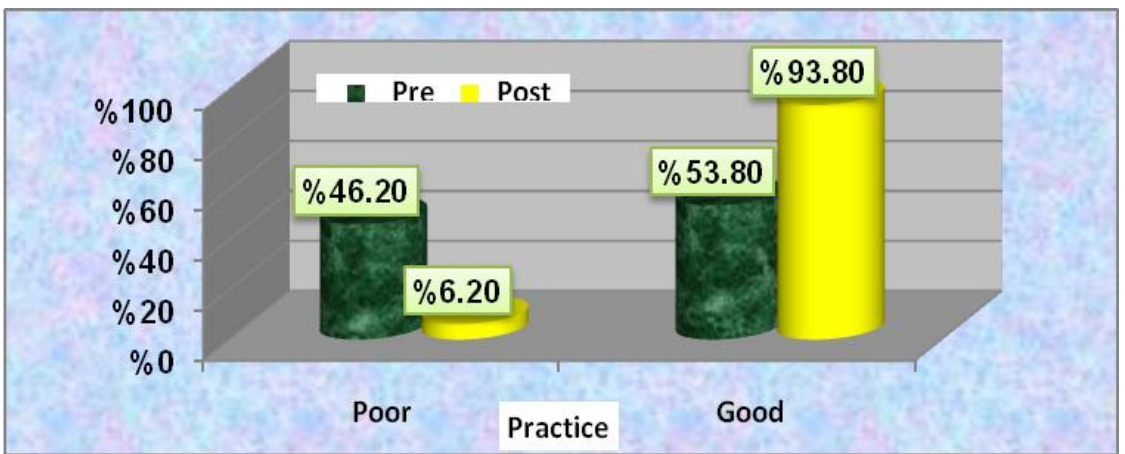

Fig. 2: Effectiveness of Nursing Intervention on Caregivers' Total Score of Practices about Epilepsy among Studied Caregivers Post Intervention.

Table 1: Effectiveness of Nursing Intervention on the Mean Score of Different Type of Feeling of Burden among Caregiver of the Studied Sample Post Intervention.

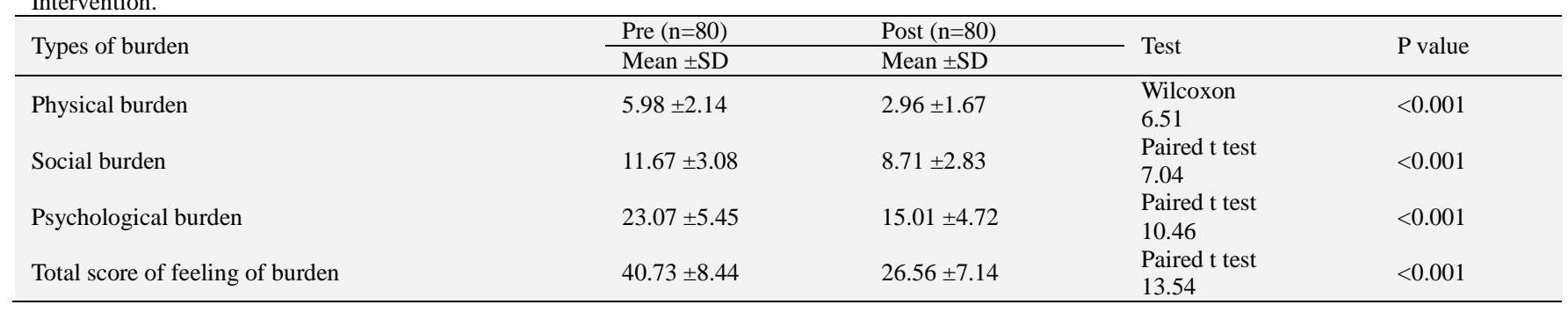

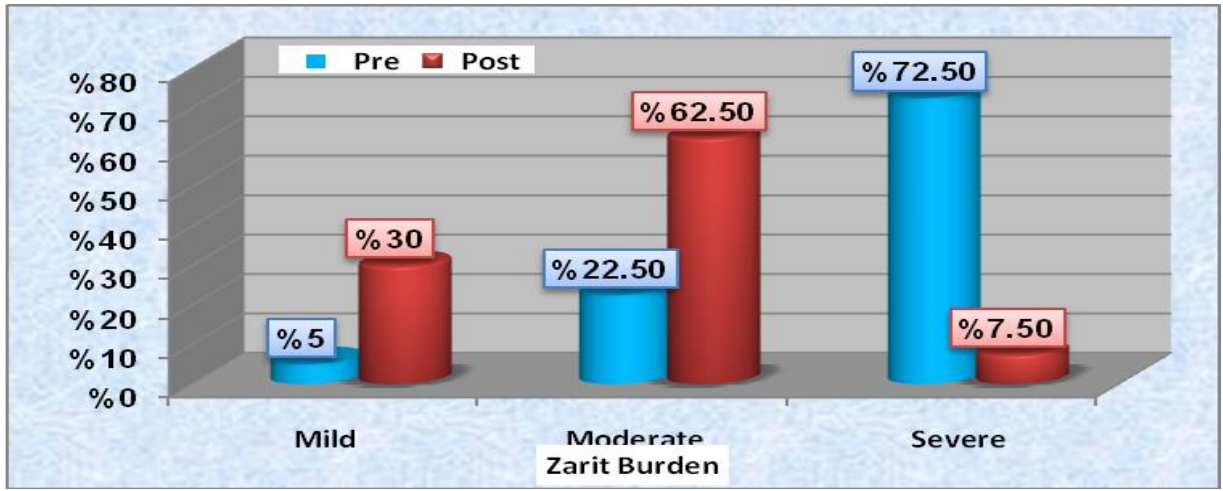

Fig. 3: Effectiveness of Nursing Intervention on Caregiver Level of Burden among Studied Caregivers Post Intervention.

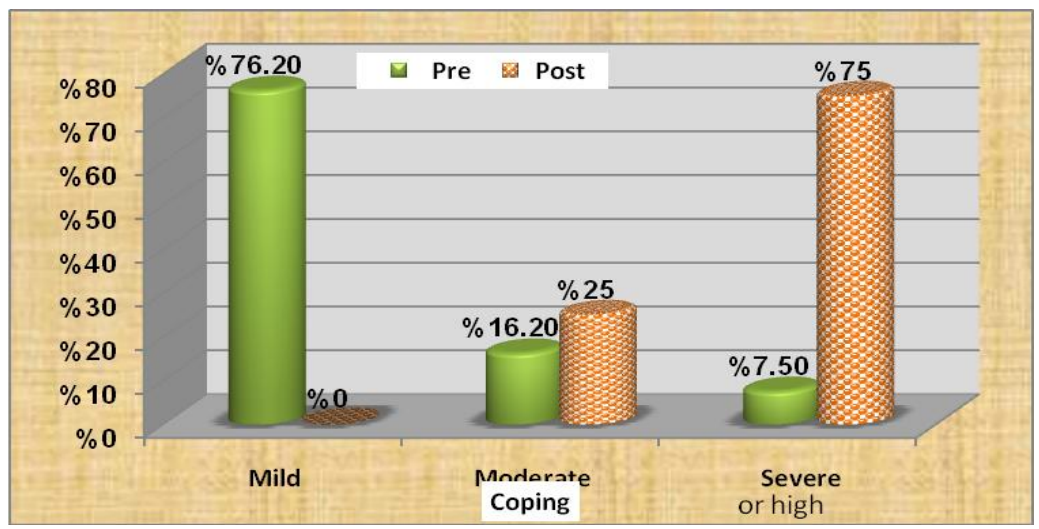

Fig. 4: Effectiveness of Nursing Intervention on Caregivers' Level of Coping among Studied Caregivers Post Intervention.

Table 2: Effectiveness of Nursing Intervention on the Mean Score of Different Type of Coping among Studied Care Giver Post Intervention.

\begin{tabular}{|c|c|c|c|c|}
\hline \multirow{2}{*}{ Types of coping } & $\operatorname{Pre}(\mathrm{n}=80)$ & Post $(n=80)$ & \multirow{2}{*}{ Test } & \multirow{2}{*}{$\begin{array}{l}P \\
\text { value }\end{array}$} \\
\hline & Mean \pm SD & Mean \pm SD & & \\
\hline - Maintaining family integration and cooperation & $\begin{array}{l}11.01 \\
\pm 4.89\end{array}$ & $\begin{array}{l}19.56 \\
\pm 5.61\end{array}$ & $\begin{array}{l}\text { Wilcoxon } \\
6.60\end{array}$ & $<0.001$ \\
\hline - Maintaining social support, self -esteem and psychological stability & $\begin{array}{l}+13.61 \\
13.04\end{array}$ & $\begin{array}{r}27.28 \\
\pm 5.28\end{array}$ & $\begin{array}{l}\text { Wilcoxon } \\
5.62\end{array}$ & $<0.001$ \\
\hline $\begin{array}{l}\text { - Understanding the medical situation through communication with other parents and consul- } \\
\text { tation with medical staff }\end{array}$ & $5.73 \pm 2.66$ & $\begin{array}{l}11.15 \\
\pm 2.56\end{array}$ & $\begin{array}{l}\text { Wilcoxon } \\
7.27\end{array}$ & $<0.001$ \\
\hline Total score of coping & $\begin{array}{l}30.36 \\
\pm 11.60\end{array}$ & $\begin{array}{l}55.75 \\
\pm 10.24\end{array}$ & $\begin{array}{l}\text { Wilcoxon } \\
\text { test } \\
7.34\end{array}$ & $<0.001$ \\
\hline
\end{tabular}


Table 3: Relationship between Socio Demographic Characteristics and Level of Burden among Studied Caregivers Pre Post Nursing Intervention.

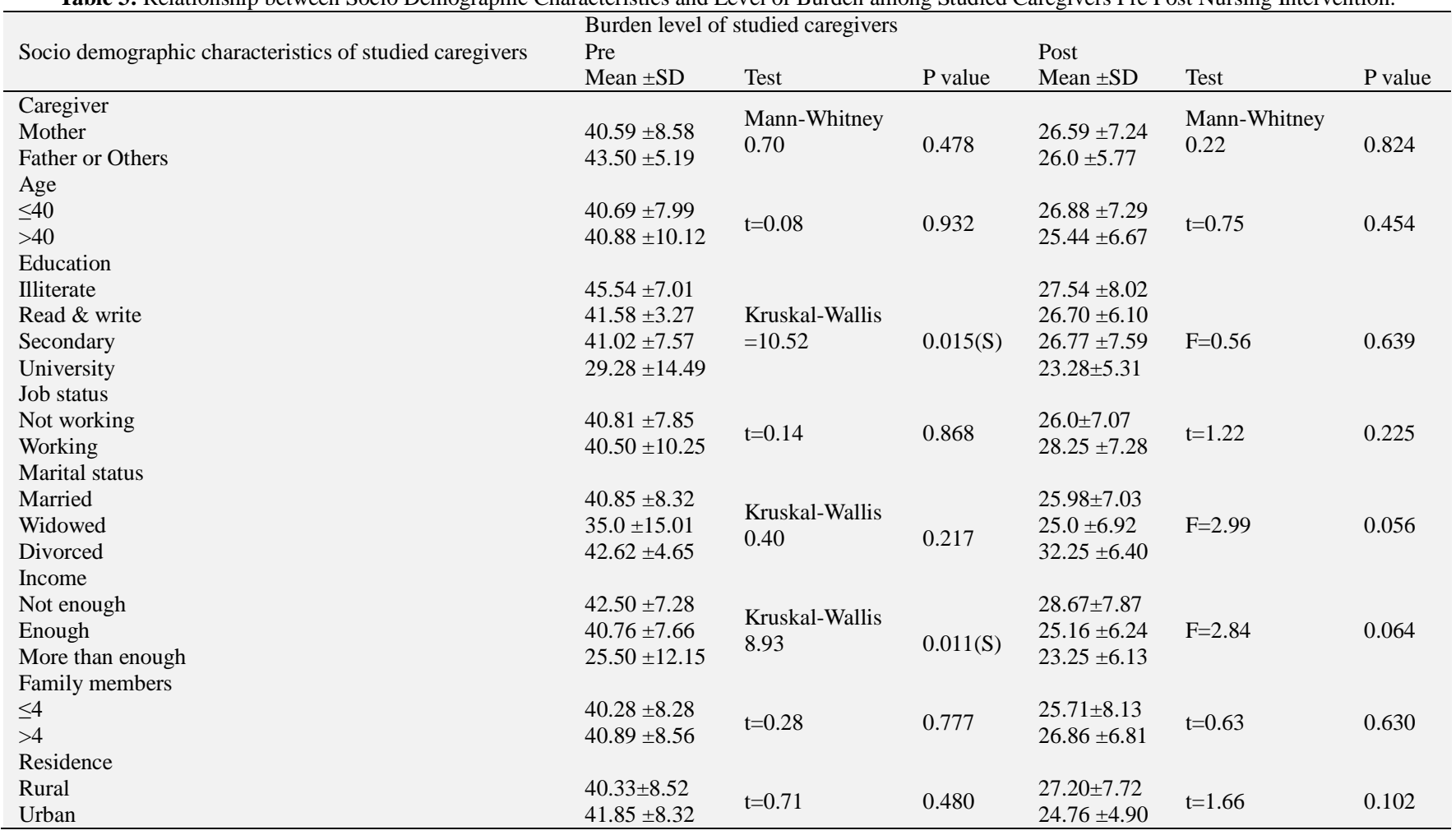

Table 4: Relationship between Studied Caregivers Socio Demographic Characteristics and Level of Coping Pre Post Nursing Intervention

\begin{tabular}{|c|c|c|c|c|c|c|}
\hline $\begin{array}{l}\text { Socio-demographic charac- } \\
\text { teristics of studied caregivers }\end{array}$ & $\begin{array}{l}\text { Coping level } \\
\text { Pre } \\
\text { Mean } \pm \text { SD }\end{array}$ & $\begin{array}{l}\text { d caregivers } \\
\text { Test }\end{array}$ & $\mathrm{P}$ value & $\begin{array}{l}\text { Post } \\
\text { Mean } \pm \text { SD }\end{array}$ & Test & $\mathrm{P}$ value \\
\hline $\begin{array}{l}\text { Caregiver } \\
\text { Mother } \\
\text { Father or others }\end{array}$ & $\begin{array}{l}30.32 \pm 11.89 \\
31.0 \pm 3.46\end{array}$ & $\begin{array}{l}\text { Mann-Whitney } \\
0.95\end{array}$ & 0.338 & $\begin{array}{l}55.42 \pm 10.41 \\
62.0 \pm 1.15\end{array}$ & $\begin{array}{l}\text { Mann-Whitney } \\
1.84\end{array}$ & 0.065 \\
\hline $\begin{array}{l}\text { Age } \\
\leq 40 \\
>40\end{array}$ & $\begin{array}{l}31.0 \pm 12.20 \\
28.16 \pm 9.23\end{array}$ & $\mathrm{t}=0.91$ & 0.365 & $\begin{array}{l}55.03 \pm 10.72 \\
58.22 \pm 8.20\end{array}$ & $\mathrm{t}=1.34$ & 0.186 \\
\hline $\begin{array}{l}\text { Education } \\
\text { Illiterate } \\
\text { Read \& write } \\
\text { Secondary } \\
\text { University } \\
\text { Uoh status }\end{array}$ & $\begin{array}{l}24.81 \pm 5.92 \\
24.70 \pm 4.63 \\
30.91 \pm 10.29 \\
49.28 \pm 17.73\end{array}$ & $\begin{array}{l}\text { Kruskal-Wallis } \\
17.21\end{array}$ & $<0.001(\mathrm{HS})$ & $\begin{array}{l}55.27 \pm 9.51 \\
56.58 \pm 7.34 \\
55.37 \pm 11.50 \\
56.85 \pm 10.56\end{array}$ & $\mathrm{~F}=0.09$ & 0.966 \\
\hline $\begin{array}{l}\text { Job status } \\
\text { Not working } \\
\text { Working }\end{array}$ & $\begin{array}{l}29.33 \pm 12.22 \\
33.45 \pm 9.08\end{array}$ & $\begin{array}{l}\text { Mann-Whitney } \\
2.25\end{array}$ & $0.024(\mathrm{~S})$ & $\begin{array}{l}56.78 \pm 9.24 \\
52.56 \pm 12.57\end{array}$ & $\mathrm{t}=1.35$ & 0.188 \\
\hline $\begin{array}{l}\text { Marital status } \\
\text { Married } \\
\text { Widowed } \\
\text { Divorced }\end{array}$ & $\begin{array}{l}30.33 \pm 12.54 \\
31.0 \pm 3.46 \\
30.25 \pm 3.15\end{array}$ & $\begin{array}{l}\text { Kruskal-Wallis } \\
3.13\end{array}$ & 0.209 & $\begin{array}{l}56.79 \pm 9.36 \\
62.50 \pm 0.57 \\
43.50 \pm 11.77\end{array}$ & $\mathrm{~F}=8.11$ & $0.001(\mathrm{~S})$ \\
\hline $\begin{array}{l}\text { Income } \\
\text { Not enough } \\
\text { Enough } \\
\text { More than enough }\end{array}$ & $\begin{array}{l}26.82 \pm 4.60 \\
30.76 \pm 12.11 \\
56.25 \pm 16.50\end{array}$ & $\begin{array}{l}\text { Kruskal-Wallis } \\
10.06\end{array}$ & $0.007(\mathrm{~S})$ & $\begin{array}{l}53.32 \pm 11.07 \\
57.66 \pm 8.78 \\
56.25 \pm 15.64\end{array}$ & $\mathrm{~F}=1.72$ & 0.185 \\
\hline $\begin{array}{l}\text { Family members } \\
\leq 4 \\
>4\end{array}$ & $\begin{array}{l}27.71 \pm 7.30 \\
31.30 \pm 12.71\end{array}$ & $\begin{array}{l}\text { Mann-Whitney } \\
0.77\end{array}$ & 0.439 & $\begin{array}{l}56.04 \pm 11.81 \\
55.64 \pm 9.74\end{array}$ & $\mathrm{t}=0.15$ & 0.878 \\
\hline $\begin{array}{l}\text { Residence } \\
\text { Rural } \\
\text { Urban }\end{array}$ & $\begin{array}{l}31.05 \pm 12.13 \\
28.42 \pm 9.98\end{array}$ & $\begin{array}{l}\text { Mann-Whitney } \\
1.32\end{array}$ & 0.187 & $\begin{array}{l}54.0 \pm 11.36 \\
60.66 \pm 2.39\end{array}$ & $\mathrm{t}=4.24$ & $\begin{array}{l}<0.001 \\
(\mathrm{HS})\end{array}$ \\
\hline
\end{tabular}

Table 5: Correlation between Knowledge, Practices and Opinions (KOP) About Epilepsy and Level of Burden Pre- Post Test Nursing Intervention among Studied Caregivers

\begin{tabular}{|c|c|c|c|c|}
\hline \multirow{3}{*}{ Studied caregivers' knowledge, attitudes and practices } & \multicolumn{4}{|c|}{ Level of burden } \\
\hline & \multicolumn{2}{|c|}{ Pre } & \multicolumn{2}{|l|}{ Post } \\
\hline & $\mathrm{R}$ & $\mathrm{P}$ value & $\mathrm{R}$ & P value \\
\hline Knowledge & -0.56 & $<0.001$ & -0.49 & $<0.001$ \\
\hline Opinions & -0.29 & 0.009 & -0.23 & 0.041 \\
\hline Practice & -0.31 & 0.005 & -0.16 & 0.143 \\
\hline
\end{tabular}


Table 6: Correlation between Knowledge, Opinions and Practices about Epilepsy and Level of Coping Pre- Post Test Nursing Intervention among Studied Caregivers

\begin{tabular}{|c|c|c|c|c|}
\hline \multirow{3}{*}{ Studied caregivers' knowledge, attitudes and practices } & \multicolumn{4}{|c|}{ Level of coping } \\
\hline & Pre & & Post & \\
\hline & $\mathrm{R}$ & $\mathrm{P}$ value & $\mathrm{R}$ & $P$ value \\
\hline Knowledge & 0.63 & $<0.001$ & 0.47 & $<0.001$ \\
\hline Opinions & 0.37 & 0.001 & 0.15 & 0.183 \\
\hline Practice & 0.32 & 0.003 & 0.21 & 0.061 \\
\hline
\end{tabular}

\section{Discussion}

The current study revealed that, more than two thirds of studied caregivers have unsatisfactory knowledge at pretest before intervention. This finding similar to finding of study conducted in Tanzanian by (Rwiza et al. 2007) who studied Knowledge, attitude and practice toward epilepsy among rural residents. They concluded that the low level of knowledge and misconceptions found among respondents, demonstrated the need for educational programs. On the other hand, the result of the current study was inconsistent with the study conducted by (Kabir et al.2005) who studied knowledge, attitude and beliefs about epilepsy among caregivers in A northern Nigerian urban community. They found that, overall one quarter of the respondents in his study had good knowledge of epilepsy whereas one third had fair knowledge. This mean that about more than half of his studied sample was knowledgeable about epilepsy. This inconsistency may be due to knowledge gaps of educational programs provided to the group of the study and lack of programs aimed to increase caregivers' knowledge about epilepsy. In addition, the results of the present study revealed that, satisfactory knowledge about epilepsy among studied caregivers was improved from more than quarter to more than three quarter after nursing intervention. This finding is congruent with study conducted in Germany by (May \&Pfafflin, 2002). Who studied the efficacy of an educational treatment program for patients with epilepsy. They reported that the Modular Service Package for Epilepsy (MOSES) program of his study, showed statistically significant improvement in Knowledge levels regarding epilepsy. This similarity could be due to that, nursing intervention of current study meets the educational needs of the subjects where most of them was expressed that they are satisfied, accepted the content of the given intervention or due to many of them were educated(secondary education) which made the understanding was easy

Regarding to practices of studied caregivers about epilepsy, near to half of studied caregivers has poor practices about epilepsy pre nursing intervention (International League Against Epilepsy and the International Bureau for Epilepsy, 2014).This result came on the same line with study conducted by (El Sharkawy et al. 2012) in Kilifi, Kenya, who studied attitudes and practices of families and health care personnel toward children with epilepsy. They stated that many parents have significant misconceptions, negative attitudes, and poor parenting practices toward children with epilepsy. This similarity could be due to lack of knowledge and negative attitude experienced by caregivers toward child with epilepsy. There was statistical significant improvement in studied caregivers practices about epilepsy post nursing intervention in which approximately more than half of studied caregivers have good practices about epilepsy pre nursing intervention that are improved to more than three quarter post nursing intervention. This mean nursing intervention, helps children and families to feel more comfortable with the disease and its effects and teaches families about ways to help increase adherence to treatment. This result came on the same line with the study carried out by (Costolo, 2011) in Arizona who studied evidence based intervention for families of children with epilepsy. He illustrated that psych-educational programs for epilepsy provide information for families about the disease and its management, provide resources and ways to manage, improve practices regarding epilepsy, cope with the disease and help children to learn about family processes and functioning when dealing with a child with epilepsy. This similarity may be due to improvement of studied caregivers' opinions toward the epileptic child after nursing intervention and the ability of researcher to properly explain and cover many items related to guidelines of how to deal with the epileptic child and how the children with epilepsy with some efforts can live normal like their peers. Also, giving the nursing education in groups (10cases/session) that allow exchanging of experiences among caregivers when facing problems of providing care (like the benefit of support group). In addition, the higher the knowledge, the better the practices are.

Regarding to feeling of burden among studied caregivers, the current study illustrated that assessing the feeling of burden due to care of epileptic children by using Zarit Burden Interviewing (ZBI) is significantly high in which the majority $(72.5 \%)$ have severe burden pre nursing intervention. This result is similar to the findings of the study conducted in Southern Nigeria by (WestphalGuitti et al. 2007) who studied quality of life and burden in caregivers of patients with epilepsy. They found that more than half of the subjects experienced high levels of burden while caring for their patients and this was significantly associated with caring for younger patients. This could be due to the majority of studied caregivers was experiencing lack of knowledge, negative attitudes and poor practices. While, this result is inconsistent with study conducted by (Martyns, 2008) who studied burden among caregivers of schizophrenic patients in Nigeria. He found that those who cared for patients in the age range "21-45" years were the most burdened than care provided to young patients. This discrimination may be due to differences of studied sample characteristics.

Furthermore, children may not appreciate the effects of their illness overall family and they are more likely to be unemployed and have to depend on the caregivers for meeting all their needs. The effects of high burden can be enormous (physical, social and psychological burden). Caregivers who experience high burden are at risk of developing emotional disorders. This finding consistent with (Ray, 2010) who studied assessment of burden of care amongst caregivers of students with epilepsy; in India. They reported that, caregivers of students with epilepsy experienced a burden involving diverse areas of functioning.

The result of the current study highlights the importance of coping strategies in influencing the stress of having a child with epilepsy or neurological problems through the analysis of this finding, coping among studied caregivers was ranged from mild to moderate and few having high coping at pretest. This analysis is similar to the analysis of the study conducted by (Westphal-Guitti, et al. 2007) who studied stress appraisal and coping in mothers of disabled and non-disabled children. They found that there is increased distress in caregivers of children with neurological disability.

The current study revealed that, nursing intervention was effective in increasing coping of studied caregivers and coping strategies. Maintenance of family integration, co-operation and optimism, social support and psychological stability and communication with other parents and medical staff were strongly associated with reduced stress relating to overall family cohesiveness, the parent perceptions of reward or satisfaction in caring for their child, and their concerns regarding their child in which many caregivers felt explaining their child disability and specific difficulties to others are beneficial The analysis of current study showed that level of education is significantly affecting the caregivers feeling of burden .This finding is supported by the study conducted by, ( Nigerian Demographic and Health Survey, 2003) who studied Problems in accessing health care and (Whitlatch et al. 2007) who studied depression and health in family caregivers: adaptation over time 
in20Nigeria. They concluded that education is indicator of high burden in their study. This might be because lack of knowledge affects the person ability to cognitively and behaviorally managing the situation, which in turn increases the feeling of burden. On the other hand, this finding is inconsistent with a study carried out by (Shore, 2004) who studied maternal adaptation to a child epilepsy, Indiana University School of Nursing, Indianapolis. They stated that educational level, economical status, and employment status did not influence QOL or burden of caregivers. This could be due to cultural and time differences. The results of this study revealed that, marital status did not show significant influence on caregivers feeling of burden .This result supported by (Mark, 2005) who studied integrative model of caregiving: How macro and micro factors affect caregivers of adults with severe and persistent mental illness in USA. He suggested that a caregiver partner might help decrease the burden through emotional support. On the other side, this study is incongruent with (Chou, 2006) \& (Sales, 2007) who studied caregiver burden: A concept analysis. Family burden and quality of life respectively. They found that marital status and family conflicts might contribute to the increase of burden on caregivers of persons with chronic disease in Japan. This discrimination might due to majority of caregivers in the present study were married which decrease the chance to compare between married and unmarried regarding to marital status and feeling of burden.

In the present study, nursing intervention was effective in reducing caregivers feeling of burden, it could be due to that it's helping caregivers to gain knowledge, changing many of caregivers' attitudes and enhancing practices of caregivers about epilepsy with trial to increase their ability to manage and deal with their feeling of burden properly. The finding of present study highlighted that, there were significant negative correlation between studied caregivers' knowledge, practices and feeling of burden regarding epilepsy as when there are good knowledge, positive attitudes and good practices, the feeling of burden among caregivers will be decreased, this is revealed that nursing intervention including educational programs and programs for psychological support seem to be effective to decrease a feeling of burden.

In addition, the finding of the current study is consistent with the study conducted by (Toseland et al. 2001) at The University of Texas at Austin School of Nursing about group interventions to support family caregivers. They found that intervention category, significantly reducing subjective burden. While, the result of the present study is not similar to the study carried out by (McCurry et al. 2001) in Washington who studied successful behavioral treatment for reported sleep problems in elderly caregivers of dementia patients. They found that no significant reduction in subjective burden following a multicomponent intervention. This discrimination also could be due to differences in sample characteristics. In general, caregivers reported that intervention is significant to alleviate stress. This effect could be due to the presence of a positive correlation between caregiver's knowledge, practice and coping after nursing intervention as when knowledge and practice improved in caregivers their ability to cope is increased. This result has come on the same line with the result of the study carried out by (Costolo, 2011). In Arizona who studied evidence based intervention for families of children with epilepsy. He illustrated that psycho-educational programs for epilepsy provide information for families about the disease and its management, provide resources and ways to manage and cope with the disease, and help children to learn about family processes and functioning when dealing with a chronic condition. The programs in his study are significant in decreasing feelings of burden and increasing adaptation and coping for children and families.

In addition, the finding of the current study is supported by a study conducted by (Newhouse et al. 2007) who studied the evidence based practice: Model and Guidelines in India. They reported that the intervention guideline recommendation was designed for parents or primary caregivers of preschool age children who have been diagnosed with epilepsy have significant and positive effect on adaptation and coping for families. They found that par- ents reporting active coping skills and use alternatives while maintaining a high commitment and responsibility to one another. In addition, the result of the current study is congruent with a study conducted by (Austin \& McDermott, 2009) in the USA who studied comparing coping (as measured by the CHIP) to parental attitude. They noted that improved attitude resulted in increased use of coping patterns; they suggested that the increased use of coping pattern strategies reflected a positive attitude of sharing feelings with others.

Coping with the care of a child with a chronic health condition occurs as parents and caregivers must cognitively and behaviorally manage the stress of comprehending the medical condition, adjusting to the diagnosis, and providing appropriate care to meet the needs of the child and family. A higher degree of burden on parents and caregivers would result in more frequent use of coping behaviors because this correlation is perceived to reflect an active effort to adjust and adapt to one's situation. This explanation also is similar to those reported by (Damrosch \& Pert 2007) in Turkey about self-reported adjustment, chronic sorrow, and coping of parents of children with chronic diseases. They noted an increase in coping with an increase in sorrow. Furthermore, this finding similar to study conducted by (Blount et al. 2008) who studied evidence-based intervention of coping and stress in pediatric psychology at the University of Wales, Cardiff. They have referred to the importance of coping strategies in reducing stress for parents or caregivers.

Finally, nurses, psychologists and specialized professionals are in a position to develop more educative strategies aimed at improving the coping abilities and decreasing the burden of patients and their caregivers.

\section{Conclusion}

Nursing intervention was effective in improving caregiver's knowledge, practices and opinions as well as feeling of burden and raising coping abilities for caregivers of children with epilepsy.

\section{Recommendation}

Additional nursing strategies are needed around the time of the diagnosis with longitudinal assessment and follow up for both caregivers and their children.

\section{References}

[1] Windland-Brown, J. \& Rhoads, J. (2007). Neurologic problems. In L. Dunphy, J. Windland- Brown, B. Porter, \& D. Thomas (Eds.), Primary care: The art and science of advanced practice nursing (pp. 61-130). F.A. Davis Company: Philadelphia.

[2] International League Against Epilepsy and the International Bureau for Epilepsy - collaborating partners of the World Health Organization"Global Campaign against Epilepsy: 2014. Available at: http://www.who.int/mental_health/management/global epilepsy complain/en/

[3] Cushner-Weinstein, S., Dassoulas, K., Salpekar,JA., Henderson, SE. Pearl, PL. \& Gaillard, WD., et al. (2008). Parenting stress and childhood epilepsy: the impact of depression, learning, and seizurerelated factors. Epilepsy Behav.13 (1).109-14. http://dx.doi.org/10.1016/j.yebeh.2008.03.010.

[4] Awad, G. \&Voruganti, L. (2008). The burden of schizophrenia on caregivers: a review. Pharmaco economics. 26(2): 149-162. http://dx.doi.org/10.2165/00019053-200826020-00005.

[5] Glueckauf, R., Fritz, S., Ecklund, E., Liss, H., Dages, P., \& Carney, P. (2009). Videoconferencing-based family counseling for rural teenagers with epilepsy: Phase 1findings. Rehabilitation Psychology, 47, 49-72. http://dx.doi.org/10.1037/0090-5550.47.1.49.

[6] Scottish Pediatric Epilepsy Network SPEN. (2013). Available from: www.spen.scot.

[7] Schachter, S. (2009). Nurses. Available at: http://www.epilepsy.com/epilepsy/team_nurses

[8] Epilepsy Foundation. (2009). Epilepsy in childhood. Retrieved from: http://www.epilepsyfoundation.org/ 
[9] Center for Disease Control and Prevention. (2009). One of the nation's most common disabling neurological conditions. Retrieved February 7, 2009 from http://www.cdc.gov/Epilepsy/

[10] Center for disease control and prevention (CDC). (2007).Statistic of epilepsy in Egypt. Available from: http//www.CDC-Epilepsy- State Activities.mht

[11] Wirrell, EC., Wood, L., Hamiwka, LD. \& Sherman, EM. (2008) Parenting stress in mothers of children with intractable epilepsy. Behav.13

(1).169-73 http://dx.doi.org/10.1016/j.yebeh.2008.02.011.

[12] Zarit, S.H., Todd, P.A., \&Zarit, J.M. (1986). Subjective burden of husband and wives as a caregivers: A longitudinal study. Gerontologist. 26, 260-66 Available from: http//www.ncbi.nlm.nih.gov.pubmed http://dx.doi.org/10.1093/geront/26.3.260.

[13] McCubbin, H.I., McCubbin, M.A., Patterson, J.M., Cauble, A.E. Wilson, L.R. \& Warwick, W. (1983). CHIP-Coping Health Inventory for Parents: An Assessment of Parental Coping Patterns in the Care of the Chronically Ill Child. Journal of Marriage and the Family, 359-370. http://dx.doi.org/10.2307/351514.

[14] Rwiza, HT. Matuja, WB. \&Kilonzo, GP. (2007). Knowledge, attitude and practice toward epilepsy among rural Tanzanian residents. Epilepsia.34: 1017-1023 http://dx.doi.org/10.1111/j.15281157.1993.tb02127.x.

[15] Kabir, M., Iliyasu, Z., Abubakar, I.S., Kabir, Z.S. \&Farinyaro, A.U. (2005).Knowledge, Attitude and Beliefs about epilepsy among adults in a northern Nigerian urban community.Annals of African Medicine.4 (3).

[16] May, TW. \&Pfafflin, M. (2002).The efficacy of an educational treatment program for patients with epilepsy [MOSES]: results of a controlled, randomized study. Modular Service Package Epilepsy.Epilepsia.43:539-49 http://dx.doi.org/10.1046/j.15281157.2002.23801.x.

[17] El Sharkawy., Newton, C. \& Hartley, S. (2012). Attitudes and practices of families and health care personnel toward children with epilepsy in Kilifi, Kenya. Epilepsy Behav.8:201-12.

[18] Costolo, M. C. (2011). Evidence Based Intervention for families of children with Epilepsy. The University of Arizona. Available at: http://arizona.openrepository.com/

[19] Westphal-Guitti, AC., Alonso, NB. \&Migliorini, RC. (2007). Quality of life and burden in caregivers of patients with epilep$\begin{array}{lll}\text { sy.JNeurosciNurs. } & 39(6): & 354-360\end{array}$ http://dx.doi.org/10.1097/01376517-200712000-00006

[20] Martyns, Y. (2008). The burden of schizophrenia on the family: a study from Nigeria. Br J Psychiatry; 161:779-782.

[21] Ray, BK., Ghoshal, M., Senapati, A., Gangopadhyay, PK. \& Roy, T. (2010). Assessment of burden of care amongst caregivers of students with epilepsy: a study from Eastern India. Neurology Asia.9 (1): 140 .

[22] Nigerian Demographic and Health Survey (NDHS). (2003). Problems in accessing health care. NDHS/National Population Commission.; p. 140

[23] Whitlatch,CJ., Feinberg, LF. \&Seberta, DS. (2007). Depression and health in family caregivers: adaptation over time. J Aging Health. 9(2):222-243. http://dx.doi.org/10.1177/089826439700900205.

[24] Shore, C. P., Austin, J. K., \& Dunn, D. W. (2004). Maternal adaptation to a child's epilepsy. Epilepsy and Behavior, 5(4), 557-568. Available

from:http://www.nursingcenter.com/lnc/journalarticle?Article_ID=8 38363 http://dx.doi.org/10.1016/i.yebeh.2004.04.015.

[25] Mark, W. W. S. (2005). Integrative model of caregiving: How macro and micro factors affect caregivers of adults with severe and persistent mental illness. American Journal of Orthopsychiatry, 75(1), 40-53. http://dx.doi.org/10.1037/0002-9432.75.1.40.

[26] Chou, K. R. (2006). Caregiver burden: A concept analysis. Journal

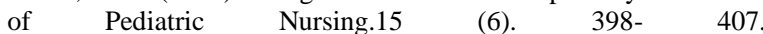
http://dx.doi.org/10.1053/jpdn.2000.16709.

[27] Sales, E. (2007). Family burden and quality of life. Quality of Life Research, 12(1), S33-S41.Retrieved from: www.nursingcenter.com/

[28] Toseland, R.W., Labrecque, M.S., Goebel, S.T., \&Whitney, M.H. (2001).An evaluation of a group program for spouses of frail elderly veterans.The Gerontologist, 32, 382-390. http://dx.doi.org/10.1093/geront/32.3.382.

[29] McCurry, S.M., Logsdon, R.G., Vitiello, M.V., \& Teri, L. (2001) Successful behavioral treatment for reported sleep problems in elderly caregivers of dementia patients: A controlled study. Journal of Gerontology: Psychological Sciences, 53B (2). 122-129. http://dx.doi.org/10.1093/geronb/53B.2.P122.
[30] Newhouse, R., Dearholt, S., Poe, S., Pugh, L., \& White, K. (2007) Johns Hopkins Nursing Evidence Based Practice: Model and Guidelines. Indianapolis: Sigma Theta Tau International.

[31] Austin, J. K., \& McDermott, N. (2009).Parental attitudes and coping behaviors in families of children with epilepsy. The Journal of Neuroscience (Online ISSN 1529-2401) is a weekly scientific journal published by the Society for Neuroscience. The journal publishes peer-reviewed empirical research articles in the field of neuroscience. Nursing. 20. 174-179.

[32] Damrosch, S. P., \& Pert 27, L. A. (2007). Self-reported adjustment, chronic sorrow, and coping of parents of children with Down syndrome. Nursing Research. 38. 25-30.

[33] Blount, RL. Simons, LE. Devine, KA.Jaaniste, T., Cohen, LL. Chambers, CT. \&Hayutin, LG. (2008). Evidence-based assessment of coping and stress in pediatric psychology. J Ped Psych. 33.10211045. http://dx.doi.org/10.1093/jpepsy/jsm071. 